\title{
The adolescence of electronic health records: Status and perspectives for large scale implementation
}

\author{
Stefan Sauermann ${ }^{1}$, Matthias Frohner ${ }^{1}$, Philipp Urbauer ${ }^{1}$, Mathias Forjan ${ }^{1}$, \\ Birgit Pohn ${ }^{1}$, Andreas Drauschke ${ }^{1}$, Alexander Mense ${ }^{1}$ \\ ${ }^{1}$ University of Applied Sciences Technikum Wien \\ Hoechstaedtplatz 5, 1200 Vienna, Austria \\ stefan.sauermann@technikum-wien.at
}

\begin{abstract}
Health informatics started to evolve decades ago with the intention to support healthcare using computers. Since then Electronic health records (EHRs) and personal health records (PHRs) have become available but widespread adoption was limited by lack of interoperability and security issues. This paper discusses the feasibility of interoperable standards based EHRs and PHRs drawing on experience from implementation projects. It outlines challenges and goals in education and implementation for the next years.
\end{abstract}

Keywords: Electronic health record, Personal health record, Interoperability, Standards, Feasibility 


\section{INTRODUCTION}

\subsection{IMPLEMENTATIONS IN THE FIELD}

Two naive pictures exist for "biomedical informatics" in the wider public: One image shows highly skilled individuals in white coats, doctors and engineers united, solving tricky problems elegantly with help from modern devices and computing methods, saving lives and curing disease. The other image shows desperate healthcare professionals bravely tackling the challenges of complex software. The software in the second image tries to support care but actually consumes additional time and effort while opening up new risks of data loss, confusion and unauthorized access to sensitive information.

One of the pioneers of the field, Edward Shortliffe, described the path of biomedical informatics in his keynote lecture at the 2012 MIE conference in Pisa [23]. It started from medical schools in the 1960s, gathered force and complexity as it spread to "informatics", and is now well established both as an industry as well as a distinctive field of research and development. Students enrolling biomedical informatics study programs today have quite a clear image of the profession that they will join.

The information and communication technology (ICT) systems and applications that we see in healthcare today have typically evolved in regional isolation, out of organizations like hospitals or companies. Very seldom we find larger networks of systems, where data flows between healthcare providers (HCPs) who do not meet personally. Today's systems rely on human individuals with oversight who can predict and verify what others will provide for them via the ICT system. Information does not automatically find its way to the place where it is needed. Human gatekeepers are still necessary who orchestrate the numerous sub-workflows in the specialized medical professions as they together provide care to individual patients.

Because of their history, the systems available today are also not easy to tailor and adapt to accommodate the requirements of specialized HCPs. In many places this has caused frustration and a general bias against ICT in healthcare. The further sections will therefore explore the available technology and the socio-political environment. This will enable to discuss near term goals that contribute to the effective adoption of the available technologies in healthcare.

\subsection{AVAILABLE TECHNOLOGY AND STANDARDS}

Numerous successful examples of artificial intelligence have been demonstrated in practice. Two decades ago the lack of interoperability standards has been identified as one main obstacle of transferring ICT methods from one site to the next [22]. Recently strong evidence has emerged that methods are available to overcome this problem.

Complementing the work of standards development organisations (SDOs, e.g. ISO, CEN, HL7) "profiling organisations" like the Integrating the Healthcare Enterprise [16] initiative and the Continua Health Alliance [6] have produced "profiles" of standards that cover selected use cases. While base standards typically deal with detailed, isolated issues, the added value of profiles is that they cover complete use cases. Using profiles implementers can therefore build complete solutions that draw from multiple and complex base standards, enabling quick adoption of state of the art and proven technologies. The records of the IHE testing events, called "Connectathons", show that 505 companies worldwide have implemented interoperable software for EHRs, radiology, laboratory, cardiology, eye 
care and others, implementing 116 integration profiles since the first Connectathon in 2001. Similarly 67 products have already reached Continua certification since the first product was certified in 2009. It has been shown that even small research groups and SMEs can successfully implement complete standards based telemonitoring systems within reasonable time and effort [25].

On the other hand large implementation projects are driven from administrations and large stakeholder groups worldwide. The European projects www.epsos.eu and www.renewinghealth.eu are piloting patient summary and medication workflows and telemonitoring on a large scale. National EHR systems are built in Austria (www.elga.gv.at), Sweden (www.cehis.se/en), and many other countries. The "EHR Incentive Program" [5] in the USA supports healthcare providers who implement standards- based ICT infrastructures and clinical decision support, triggering a significant movement towards implementation and certification of innovative and interoperable software products among vendors. These national initiatives typically do not use the same set of IT architectures for connecting local EHRs. However progress is visible. For example the epSOS infrastructure uses a common set of interoperability standards and generates a common base that can be extended over time.

\subsection{SOCIO-POLITICAL ENVIRONMENT}

Students of today know rotary dials on telephones from the museum only. They watched the record stratospheric dive in October 2012 live on a mobile device and commented to friends via twitter and SMS when they rode on the bus [24]. In contrast, the doctors, politicians, company leaders, patients and lecturers of today sent their first email when were already firmly settled in the early stages of a professional career. The technology lifecycles have shortened dramatically.

On the other hand the influence of unhealthy lifestyles and demographic change on the health status of populations is well documented [21]. Administrations are actively searching and evaluating strategies to address sedentary lifestyles, unhealthy nutrition and other negative influences on public health on a large scale [10]. The focus on lifestyle and prevention demands to extend the activities well beyond the reach of healthcare professions. Many other groups will need to contribute, with the individuals and patients themselves as the main advocates of their own health. Successful solutions need to consider the wide variety of user needs and capabilities. State of the art ICT is deeply embedded into these activities. A wide variety of health-related software products that use mobile technologies have already reached the market and there are strong indicators for further growth in the near future [20].

The goal of this work was to assess the status of standards based semantic interoperability for EHRs and PHRs on a large scale in order to better understand the extent of implementation we can expect in the near future.

The underlying thesis of this work is that only within the last ten years technical specifications have become available that enable large scale implementation of EHRs and PHRs. Technical specifications in many variants have been available for much longer, for example from ISO [19], CEN [2], HL 7 [11], IHE [16], and Continua [6]. Nevertheless large scale implementation is not common so far. The specifications alone therefore are not useful as sufficient evidence for large scale implementation. Therefore additionally to the specifications publicly available testing tools and evidence of implementation and testing activities were used as evidence. 


\section{MATERIALS AND METHODS:}

EHR and PHR implementation projects were selected and studied. Selection criteria were:

- The projects shall use specifications that are harmonised within an internationally recognised organisation, for example ISO [19], CEN [2], HL7 [11], IHE [16], and Continua [6].

- The projects shall target EHR or PHR implementation on a national or international scale, potentially serving millions of patients. The necessary stakeholders shall be represented in the project.

- Projects shall involve implementation steps that are documented and publicly available

- Documentation about testing activities of the project shall be available publicly

- The authors shall be involved in the project, so that feasibility of implementation by SMEs may be studied

The following projects were selected:

- Austrian eHealth initiative: recommendations for an eHealth strategy for Austria (EHI, 0)

- Implementation guides for medical reports in HL7 CDA format for the Austrian EHR "ELGA" (ELGA CDA, http://www.elga.gv.at/index.php?id=28)

- European patients smart open services (epSOS, http://www.epsos.eu)

- Healthy Interoperability (HIO, [25])

During the projects information was collected and reviewed according to the following questions:

- Which stakeholders (clinical users, software vendors, administration) were involved and which specifications were used?

- How much time did it take to generate the specifications?

- Which level of detail was reached (basic architecture outline, detailed content and transaction specifications)

- In which way were the specifications then implemented (project was formed, legal frameworks decided)?

- Are formal testing tools for the specifications available?

- Was the conformance of the implementations formally tested?

- Is re-use of the specifications among the projects documented?

Only publicly available evidence documents were reviewed. These observations were then used to discuss the feasibility of large scale implementation of semantic interoperability in comparison to the situation described by Shortliffe in 1993 [22]. 


\section{RESULTS}

\subsection{SPECIFICATIONS, STAKEHOLDER INVOLVEMENT, LEVEL OF DETAIL}

In all projects interoperability specifications were defined for specific applications. In all projects relevant stakeholders were engaged in the development and agreed on the resulting specifications. In three of the four projects clinical users, software vendors as well as administration was involved. The HIO project represents a SME implementing available specifications and therefore includes only one software vendor. Tab. 1 summarises these findings and lists the reviewed sources.

\begin{tabular}{|c|c|c|c|c|}
\hline Project & Type of stakeholders & Duration & Specifications & Level of implementation \\
\hline EHI & $\begin{array}{l}>10 \text { clinical users, } \\
>10 \text { software } \\
\text { vendors, } \\
\text { administration }\end{array}$ & $\begin{array}{l}2005- \\
2007\end{array}$ & $\begin{array}{l}\text { Recommendations, } \\
\text { architectural framework } 0 \text {, } \\
\text { national recommendation } \\
\text { on standards [3] }\end{array}$ & $\begin{array}{l}\text { Only conceptive, taken } \\
\text { further within ELGA }\end{array}$ \\
\hline $\begin{array}{l}\text { ELGA } \\
\text { CDA }\end{array}$ & $\begin{array}{l}>10 \text { clinical users, } \\
>10 \text { software } \\
\text { vendors, } \\
\text { administration }\end{array}$ & $\begin{array}{l}\text { Since } \\
2007\end{array}$ & $\begin{array}{l}\text { Technical specifications, } \\
\text { testing tools }[8], \text { legal } \\
\text { framework }[2],[11]\end{array}$ & $\begin{array}{l}\text { Implementation under } \\
\text { way, operation in } \\
\text { Austrian hospitals } \\
\text { expected early } 2015\end{array}$ \\
\hline epSOS & $\begin{array}{l}>10 \text { clinical users, } \\
>10 \text { software } \\
\text { vendors, } \\
\text { administration }\end{array}$ & $\begin{array}{l}\text { Since } \\
2008\end{array}$ & $\begin{array}{l}\text { Technical Specifications } \\
{[11] \text {, legal requirements }} \\
{[12]}\end{array}$ & Implemented, operative \\
\hline $\mathrm{HIO}$ & 1 Software vendor & $\begin{array}{l}2009- \\
2012\end{array}$ & $\begin{array}{l}\text { Re-used available } \\
\text { specifications [25] }\end{array}$ & $\begin{array}{l}\text { Software implemented } \\
{[25]}\end{array}$ \\
\hline
\end{tabular}

Tab. 1. Specifications resulting from projects, overview.

The projects that were studied have different scopes. EHI was a conceptive approach that only resulted in very generic specifications. However all necessary stakeholders were represented and agreed on the results. All other projects targeted and reached implementations. Especially ELGA CDA and epSOS represent large scale projects that may be used to compare future large scale activities.

In three of the projects the specifications development lasted at least 2 years. HIO had a similar duration than the other projects, but only a small part of that time was spent on the development of specifications. HIO represents a typical SME activity in that it re-used existing specification documents to develop an application that uses an available infrastructure provided by others as described in [25]. 


\subsection{TESTING TOOLS, TESTING ACTIVITY}

In all projects where implementation occurred, testing specifications are available. Only within epSOS interoperability was formally tested. However testing specifications for the specifications that were used in HIO are also available. A list of certified products is publicly available. Tab. 2 summarises the results and the related references.

\begin{tabular}{|c|c|c|c|}
\hline Project & Testing tools & Testing activities & Test results publicly available \\
\hline EHI & Not applicable & Not applicable & Not applicable \\
\hline $\begin{array}{l}\text { ELGA } \\
\text { CDA }\end{array}$ & $\begin{array}{l}\text { Schematrons } \\
\text { available [9] }\end{array}$ & $\begin{array}{l}\text { Only informal tests at } \\
\text { software vendors during } \\
\text { development }\end{array}$ & none \\
\hline epSOS & $\begin{array}{l}\text { Test specifications } \\
{[13]}\end{array}$ & $\begin{array}{l}\text { Yearly formal epSOS } \\
\text { testing events took place } \\
\text { since } 2010\end{array}$ & $\begin{array}{l}\text { Only overviews, e.g. [18], } \\
\text { IHE Connectathon Results } \\
\text { Database [17] addresses } \\
\text { specifications only partly }\end{array}$ \\
\hline $\mathrm{HIO}$ & $\begin{array}{l}\text { Continua } \\
\text { Certification } \\
\text { Specification [7] }\end{array}$ & $\begin{array}{l}\text { Testing occurs regularly } \\
\text { at Plugfests and within } \\
\text { certification activities }\end{array}$ & $\begin{array}{l}{[25], \text { Continua certified }} \\
\text { products database }[8]\end{array}$ \\
\hline
\end{tabular}

Tab. 2. Testing specifications and activities within projects, overview.

\subsection{RE-USE OF SPECIFICATIONS}

Re-use of existing specifications was found in all projects. Re-use between the studied projects only occurred in the ELGA CDA project in that it re-used the basic recommendations that resulted from the EHI. However the total project durations are similar in all studied projects. Successful re-use of specifications was only possible after the source and target projects thoroughly analysed these issues. Tab. 3 shows an overview of the most important specifications that were re-used in each project.

\begin{tabular}{ll}
\hline Project & Re-used existing specifications \\
\hline EHI & HL7 CDA document architecture [15] \\
& IHE IT Technical framework [16] \\
ELGA & EHI architectural guidance 0, \\
CDA & EHI recommendations for standards [3], \\
& IHE IT Technical Framework [16], \\
& HL7 CDA document architecture [15] \\
& \\
epSOS & IHE IT Technical Framework [16], \\
& HL7 CDA document architecture [15]
\end{tabular}




\begin{tabular}{ll}
\hline HIO & $\begin{array}{l}\text { IHE IT Technical Framework [16], } \\
\text { Continua design Guidelines [6] }\end{array}$ \\
\hline
\end{tabular}

Tab. 3. Re-use of existing specifications in projects.

\section{DISCUSSION AND CONCLUSIONS}

Based on the observations from the projects that were studied it was found that semantic interoperability for EHRs and PHRs on both national and international scale is possible in practice. This is supported by the fact that software implementations were formally tested and are conformant to the interoperability specifications of all projects that involved implementations.

From the results summarised in Tab. 1 it can be concluded that specifications are available both for EHRs and PHRs. Tab. 2 additionally shows that methods are available and actively used to formally test implementations against these specifications.

Tab. 3 shows a high level of overlap between the projects that were studied. This indicates that a wider harmonisation of specifications has occurred: In 1993 Shortliffe expected that artificial intelligence in medicine will become a reality only after "... the infrastructure for introducing computational tools in medicine has been put in place by visionary leaders, who understand the importance of networking, integration, shared access to patient data bases, and the use of standards for data-exchange, communications and knowledge-sharing" [22]. The results of this work show that substantial harmonisation effort has provided visible results since 1993. Common interoperability standards therefore have moved from a faint hope to partial reality.

It was however found that substantial learning efforts were still necessary even if existing specifications were re-used. This may be attributed to the fact that the necessary specifications cover very wide topics and constitute a substantial amount of information, if reviewed in total. Additional specification effort will be necessary to extend the defined functionality.

In this situation it seems reasonable to focus on a common learning effort that involves individuals, administrations, healthcare providers, industry, academia and many other forces. As we go along, we need to:

- further explore and share interoperability technologies and standards,

- actively engage users and solution providers of all origins,

- learn from practice,

- document and share experience,

- sustain motivation and provide encouragement to all involved.

This work shows that the skills required for this exercise are available within biomedical informatics as well as in many other disciplines. They have been exercised in first projects. The challenge of the coming years will be to enrich the "low hanging fruit" applications and further empower harmonisation work so that co-operation occurs during implementation. 
Today we enjoy the luxury of all necessary components being ready, tested and available to all interested communities within a reasonable time and effort. Never before has this been the case. Within the next few years we will learn if and how fast we will be able to further develop common visions and put them into practice. We will definitely see further obstacles that lie hidden in the dark. We may however be surprised about the speed and success of progress.

\section{REFERENCES}

[1] ARBEITSKREIS 1 DER ÖSTERREICHISCHEN EHEALTH INITIATIVE, Pfeiffer, P.; Sauermann, S.; Leodolter, W.; Seeburger, H.; Hoellebauer, H.; Deutsch, E.; Pjeta, O. \& Holler, G. Pfeiffer, K. (Ed.). Empfehlung für eine österreichische e-Health Strategie - Eine Informations- und Kommunikationsstrategie für ein modernes österreichisches Gesundheitswesen. Bericht der Österreichischen e-Health Initiative, Stand Jänner 2007. 2007, 1-58. [cit. 2013-05-27] Online:

http://ehi.adv.at/fileadmin/user_upload/adv_author/pdfs/konferenz20070126/Strategie_Empfe hlung der_e-Health-Initiative Oesterreich_20070126_v2 02.pdf

[2] BUNDESGESETZ BGBL. Nr. 111/2012 (Austrian law): Elektronische GesundheitsakteGesetz - ELGA-G. [cit. 2013-05-27] Online: http://www.elga.gv.at/fileadmin/user_upload/uploads/download_Papers/Gesetze_u.a._Rechtsg rundlagen/BGBLA_2012_I_111.pdf

[3] BUNDESMINISTERIUM FÜR GESUNDHEIT FRAUEN UND JUGEND (Austrian Federal Ministry of Health). Standards im österreichischen Gesundheitswesen. 11.6.2007. Document ID GFJ-72300/0025-I/A/15/20075/2007. [cit. 2013-05-27] Online:

http://www.elga.gv.at/fileadmin/user_upload/uploads/download_Papers/Gesetze_u.a._Rechtsg rundlagen/BMGFJ_Standards_2007-06-11.pdf

[4] CEN/TC 251. Published standards. [cit. 2013-05-27] Online: http://www.cen.eu/CEN/Sectors/TechnicalCommitteesWorkshops/CENTechnicalCommittees/ Pages/Standards.aspx?param $=6232 \&$ title $=\mathrm{CEN} / \mathrm{TC}+251$

[5] CENTERS FOR MEDICARE AND MEDICAID SERVICES (CMS). The Official Web Site for the Medicare and Medicaid Electronic Health Records (EHR) Incentive Programs. CMS, Baltimore, MD, USA. [cit. 2013-05-27] Online: http://www.cms.gov/Regulations-andGuidance/Legislation/EHRIncentivePrograms/index.html?redirect=/ehrincentiveprograms/

[6] CONTINUA HEALTH ALLIANCE. Continua Design Guidelines Version 2012. 2012. [cit. 2013-05-27] Online: http://www.continuaalliance.org/products/design-guidelines

[7] CONTINUA HEALTH ALLIANCE. Certification Specification. [cit. 2013-05-27] Online: https://cw.continuaalliance.org/wg/TCWG/documentRevision/download/10695

[8] CONTINUA HEALTH ALLIANCE. Certified Products Showcase. [cit. 2013-05-27] Online: http://www.continuaalliance.org/products/product-showcase

[9] ELGA GmbH (Elektronische Gesundheitsakte Österreich). Harmonisierungsarbeit für medizinische Dokumente. [cit. 2013-05-27] Online: http://www.elga.gv.at/index.php?id=28

[10] EUROPEAN COMMISSION (EC). ICT Challenge 5: ICT for Health, Ageing Well, Inclusion and Governance. ICT - Information and Communication Technologies in FP7, Work Programme 2013, homepage, last update 2012-07-31. [cit. 2013-05-27] Online: http://cordis.europa.eu/fp7/ict/programme/challenge5 en.html

[11] EUROPEAN PATIENTS SMART OPEN SERVICES (European Project epSOS). Deliverable D3.4.2, epSOS Common Components Specification. 16.7.2010. [cit. 2013-05-27] Online: 
http://www.epsos.eu/uploads/tx epsosfileshare/D3.4.2 epSOS_Common_Components Specif ication 01.pdf

[12] EUROPEAN PATIENTS SMART OPEN SERVICES (European Project epSOS). Deliverable D2.1.1 - Legal and Regulatory Requirements at EU level. 24.2.2012. [cit. 2013-05-27] Online: http://www.epsos.eu/uploads/tx epsosfileshare/D2.1.1_legal_requ final 01.pdf

[13] EUROPEAN PATIENTS SMART OPEN SERVICES (European Project epSOS). Deliverable D3.9.2 - Testing Methodology, Test Plan and Tools. 15.0.2010. [cit. 2013-05-27] Online: http://www.epsos.eu/fileadmin/content/pdf/deliverables/D3.9.2 Testing_Methodology Test_P lan and Tools.pdf

[14] GESUNDHEITSTELEMATIKVERORDNUNG - GTELV 2012. [cit. 2013-05-27] Online: http://www.elga.gv.at/fileadmin/user_upload/uploads/download Papers/Gesetze u.a._Rechtsg rundlagen/BGBLA_2012_II_483.pdf

[15] HEALTH LEVEL SEVEN (HL7) INTERNATIONAL. Homepage. [cit. 2013-05-27] Online: http://www.hl7.org/

[16] INTEGRATING THE HEALTHCARE ENTERPRISE (IHE). IHE Technical Frameworks. [cit. 2013-05-27] Online: http://www.ihe.net/Technical_Framework/index.cfm

[17] INTEGRATING THE HEALTHCARE ENTERPRISE (IHE). Connectathon results browsing. [cit. 2013-05-27] Online: http://connectathon-results.ihe.net/

[18] INTEGRATING THE HEALTHCARE ENTERPRISE (IHE). IHE-Europe Connectathon 2013 enables robust, in-depth testing for HIT interoperability. Press release 6.5.2013. [cit. 2013-05-27] Online: http://www.ihe-europe.net/sites/default/files/IHE-

Europe\%20Connectathon\%202013\%20Press\%20Release.pdf

[19] ISO/TC 215 HEALTH INFORMATICS. Homepage. [cit. 2013-05-27] Online: http://www.iso.org/iso/iso technical committee?commid $=54960$

[20] LIEBERT, M. A. Report sees fastest growth at home, as telemed swells to \$23B by 2015. Telemedicine and e-Health News Alert, 2011. [cit. 2013-05-27] Online: http://www.telemedicinealerts.com/Archives/2011/Feb_11/Feb 18 11.htm

[21] PINIEWSKI, B.; CODAGNONE, C.; OSIMO, D. Nudging lifestyles for better health outcomes: crowd sourced data and persuasive technologies for behavioural change European Commission. Joint Research Centre, Institute for Prospective Technological Studies, 2011, 178. [cit. 2013-05-27] Online: http://ftp.jrc.es/EURdoc/JRC64206.pdf

[22] SHORTLIFFE E.H. The adolescence of AI in Medicine: Will the field come of age in the 90s? Artificial Intell.Med. 5, 1993, 93-105.

[23] SHORTLIFFE, E.H. The Future of Biomedical Informatics: A Perspective from Academia. In: Quality of Life through Quality of Information. J. Mantas et al. (Eds.), IOS Press, 2012, European Federation for Medical Informatics and IOS Press. Proceedings of the 24th European Medical Informatics Conference - MIE2012 - in Pisa, Italy, August 26th -29th, 2012 doi:10.3233/978-1-61499-101-4-19.

[24] SMITH C. Red Bull Stratos YouTube Live Stream Attracts Record Number Of Viewers. The Huffingtom Post, New York City, United States. 14th October 2012. [cit. 2013-05-27] Online: http://www.huffingtonpost.com/2012/10/14/red-bull-stratos-youtube_n_1965375.html

[25] URBAUER, P.; FROHNER, M.; FORJAN, M.; POHN, B.; SAUERMANN, S.; MENSE, A. A Closer Look on Standards Based Personal Health Device Communication: A Résumé over Four Years Implementing Telemonitoring Solutions. European Journal for Biomedical Informatics, Vol. 8(2012), Issue 3, pp. 65-70, ISSN 1801-5603. 